
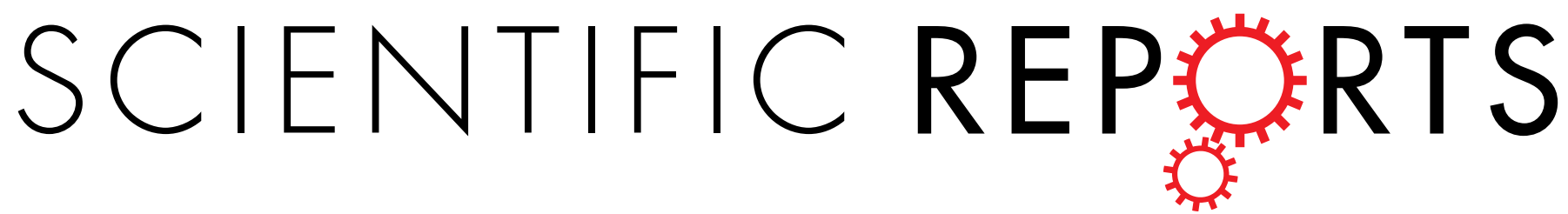

\title{
OPEN
}

Received: 13 September 2016

Accepted: 29 November 2016

Published: 03 January 2017

\section{In situ degradation of antibiotic residues in medical intravenous infusion bottles using high energy electron beam irradiation}

\author{
Min Wang ${ }^{1,2}$, Lele Zhang ${ }^{3}$, Guilong Zhang ${ }^{1,2}$, Tao Pang ${ }^{4}$, Xin Zhang ${ }^{3}$, Dongqing Cai ${ }^{1,2,5}$ \& \\ Zhengyan $\mathrm{Wu}^{1,2,5}$
}

This study reported an immediate approach for the degradation of three antibiotic (amoxicillin, ofloxacin, and cefradine) residues in medical intravenous infusion bottles (MIIBs) using high energy electron beam (HEEB) irradiation. The effects of irradiation doses, initial concentrations, initial $\mathrm{pH}$, and scavengers of active radicals on the degradation of three antibiotic residues (ARs) were investigated, and the results displayed that $97.02 \%, 97.61 \%$ and $96.87 \%$ of amoxicillin, ofloxacin, and cefradine residues could be degraded in situ through HEEB irradiation respectively. Fourier transform infrared spectroscopy (FTIR) and high performance liquid chromatography-mass spectrometry (HPLC-MS) analysis demonstrated that ARs were mainly decomposed into inorganic ions and alkanes. Typically, the detailed degradation mechanism of ARs was also investigated, and the dominant active particle inducing the degradation of antibiotics during the HEEB irradiation process was demonstrated to be hydroxyl radical.

Antibiotics have been widely used in the treatment of bacterial infections for both humans and animals. According to previous studies, 100,000 to 200,000 tons of antibiotics are used around the world every year ${ }^{1}$. Hence, plenty of medical intravenous infusion bottles (MIIBs) with antibiotic residues (ARs) were generated and exposed to environment, causing extremely harmful effects on human health (arthropathy, nephropathy, mutagenic effect, damage of central nervous system, growing of antibiotic-resistant bacteria) and ecological balance (damage on the structure of microbial community) $)^{2-7}$. Therefore, it is rather important to develop an efficient method to degrade ARs.

In the past a few years, several approaches for degradation of antibiotics have been developed mainly through adsorption, catalytical degradation, and biodegradation ${ }^{8-11}$. Those could degrade or remove antibiotics to different extents, however they displayed a few disadvantages: high cost and secondary pollution for the former method, low efficiency and strict condition for the latter two methods ${ }^{12-14}$. Recently, high energy electron beam (HEEB) irradiation has attracted more and more attention due to its properties of high efficiency, clean, low cost, and available for batch processing ${ }^{15-17}$. Furthermore, HEEB irradiation can facilely generate highly reactive species in aqueous solution, such as reductive solvated electron $\left(\mathrm{e}_{\mathrm{aq}}^{-}\right)$, hydrogen atom $(\mathrm{H} \cdot)$, and oxidative hydroxyl radical $(\mathrm{OH} \cdot)$, which are favor to the degradation of organic pollutants. Therefore, we decided to treat the ARs by HEEB irradiation.

Here, the application of HEEB irradiation on the immediate and in situ degradation of ARs in MIIBs has been reported. This work will lower the cost of the treatment of ARs because ARs in MIIBs are easily to be collected and in situ degraded. Amoxicillin (AMX), ofloxacin (OFL), and cefradine (CED) are selected as representative antibiotics of $\beta$-lactams, cephalosporins, and quinolones, respectively, which have been widely used in human

${ }^{1}$ Key Laboratory of Ion Beam Bioengineering, Hefei Institutes of Physical Science, Chinese Academy of Sciences, Hefei 230031, People's Republic of China. 'University of Science and Technology of China, Hefei 230026, People's Republic of China. ${ }^{3}$ School of Life Sciences, Anhui Agricultural University, Hefei 230036, People's Republic of China. ${ }^{4}$ Anhui Jianghuai Automobile Co., Ltd, Hefei 230022, People's Republic of China. ${ }^{5}$ Key Laboratory of Environmental Toxicology and Pollution Control Technology of Anhui Province, Hefei Institutes of Physical Science, Chinese Academy of Sciences, Hefei 230031, People's Republic of China. Correspondence and requests for materials should be addressed to X.Z. (email: xinzhang@ahau.edu.cn) or D.C. (email: dqcai@ipp.ac.cn) or Z.W. (email: zywu@ipp.ac.cn) 


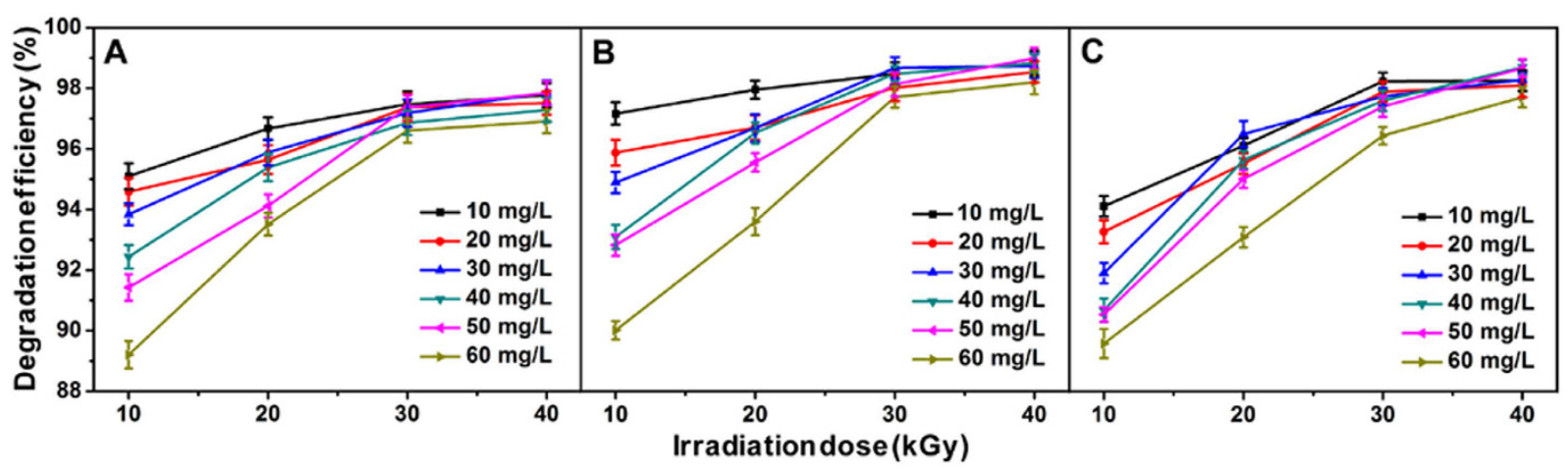

Figure 1. Degradation efficiencies of $\operatorname{AMX}(\mathbf{A})$, OFL (B) and CED (C) treated by HEEB irradiation with different doses.

and veterinary medicines for their effective broad spectrum against a wide variety of microorganisms ${ }^{1,3,6,18}$. In the present study, HEEB displayed fine performance on the degradation of ARs in MIIBs. Meanwhile, the effects of initial concentrations of antibiotics, HEEB irradiation doses, $\mathrm{pH}$ of initial solutions, and common coexistent substances on AR degradation behavior were studied in detail to obtain the optimal degradation condition, and the reaction mechanism was also investigated.

\section{Results and Discussion}

Effects of HEEB irradiation dose on the degradation of AR. A batch of experiments were conducted to investigate the effects of HEEB irradiation dose and initial concentrations of antibiotics on the DEs of ARs. As shown in Fig. 1, the DEs of ARs increased with HEEB irradiation dose at first ( $<30 \mathrm{kGy})$ and became relatively stable afterwards $(>30 \mathrm{kGy})$, which was probably because the amounts of active particles generated in the AR solutions increased with irradiation dose $(<30 \mathrm{kGy})$, and then became almost sufficient for the degradation of all the ARs $(>30 \mathrm{kGy})$. Additionally, when the initial concentration of AR was below $50 \mathrm{mg} \mathrm{L}^{-1}$, the DE of each AR almost decreased with the increasing initial AR concentration when the irradiation dose was lower than $20 \mathrm{kGy}$, and reached nearly same value when the dose was higher than $30 \mathrm{kGy}$. This was because the ratio (amounts of active particles/amounts of AR molecules) decreased with the increasing initial AR concentrations when the dose was lower than $20 \mathrm{kGy}$, while the active particles were sufficient for the degradation of almost all the AR molecules with dose higher than $30 \mathrm{kGy}$. When the initial concentration of $\mathrm{AR}$ was $60 \mathrm{mg} \mathrm{L}^{-1}$, the DE of AR appeared lower compared with AR with the concentration below $50 \mathrm{mg} \mathrm{L}^{-1}$. Therefore, the optimal dose of HEEB irradiation was $30 \mathrm{kGy}$ and the optimal initial concentrations of three ARs were $50 \mathrm{mg} \mathrm{L}^{-1}$. Therein, at irradiation dose of $30 \mathrm{kGy}$, the DE order was OFL $>$ AMX $>C E D$, which was probably attributed to their molecular structures.

Effect of $\mathrm{pH}$ on the degradation of AR. The influence of $\mathrm{pH}$ on the degradation performance of ARs was also investigated. Fig. 2A-C showed the UV absorption spectra of AMX, OFL, and CED at different $\mathrm{pH}$ values respectively. It could be seen that the absorption intensities of AMX, OFL, and CED all decreased with the increasing $\mathrm{pH}$. Accordingly, the DEs of AMX, OFL, and CED increased with $\mathrm{pH}$ (Fig. 2D), which was probably because alkaline condition could effectively promote the dissociation of AR molecules and the generation of active particles in the solution, and meanwhile the dissociated AR molecules tended to be degraded by these active particles ${ }^{19}$. Considering the slow increasing trend when $\mathrm{pH}$ was higher than 9.0 , the $\mathrm{pH}$ for the degradation of ARs was selected as 9.0.

Degradation products investigation. FTIR analysis. FTIR measurement was performed to investigate the degradation products of ARs. Fig. 3b showed the standard spectrum of AMX, the intensified peaks at 1687, 1776 , and $3398 \mathrm{~cm}^{-1}$ were corresponding to $\mathrm{C}=\mathrm{O}$ of $\mathrm{N}-\mathrm{C}=\mathrm{O}, \mathrm{C}=\mathrm{O}$ of $\mathrm{HO}-\mathrm{C}=\mathrm{O}$, and $-\mathrm{OH}$ of Ar-OH, respectively ${ }^{6}$. As shown in Fig. 3d, the absorption peaks at 1622 and $1713 \mathrm{~cm}^{-1}$ were ascribed to $\mathrm{C}=\mathrm{O}$ of $-\mathrm{COOH}$ and $-\mathrm{C}=\mathrm{O}-$ of $\mathrm{OFL}^{20}$. Additionally, a series of characteristic absorption peaks at $470,664,787,1606,1687$, and $1773 \mathrm{~cm}^{-1}$ of CED were clearly observed in Fig. 3f. Moreover, the FTIR spectra of degradation products of AMX, OFL, and CED after HEEB irradiation exhibited the similar absorption peaks as shown in Fig. 3a,c and e, respectively, suggesting that the degradation products possessed the similar chemical structures. According to previous studies ${ }^{6,20}$, the absorption peaks at $3400 \mathrm{~cm}^{-1}$ could be assigned to the stretching vibration of - $\mathrm{OH}$, and the peaks at 1450,2900 , and $1360 \mathrm{~cm}^{-1}$ confirmed the existence of $-\mathrm{CH}_{2}$ and $-\mathrm{CH}_{3}$ in the degradation products. Meanwhile, the absorption peaks between 3100 and $3010 \mathrm{~cm}^{-1}$ of AMX, OFL, and CED disappeared in the spectra of degradation products, indicating the destruction of unsaturated hydrocarbons in antibiotics. These results indicated that the degradation products of ARs after HEEB irradiation included saturated alkane.

HPLC/MS analysis. HPLC measurement was performed to investigate the degradation products of ARs. It could be seen clearly in Fig. 4Aa-Ac that the main peaks of AMX, OFL, and CED possessed the same retention time, indicating that three antibiotics possessed the same products after degradation. Meanwhile, the products of AMX, OFL, and CED after HPLC measurement at retention time of 9.157 min were analyzed by MS, which showing 

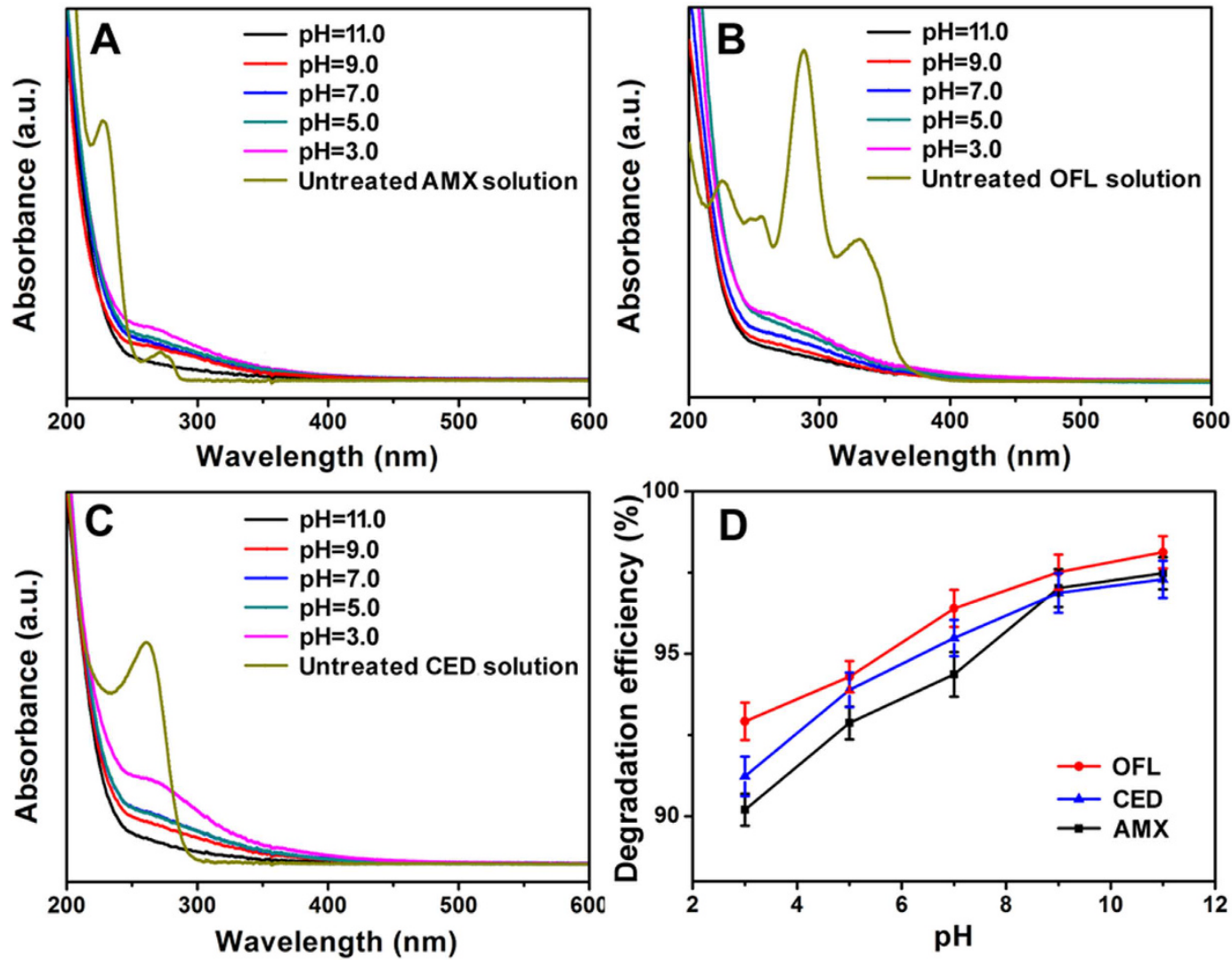

Figure 2. UV absorption spectra of $\operatorname{AMX}(\mathbf{A}), \mathrm{OFL}(\mathbf{B}), \mathrm{CED}(\mathbf{C})$, and the DEs (D) of ARs $\left(50 \mathrm{mg} \mathrm{L}^{-1}\right)$ at different $\mathrm{pH}$ with irradiation dose of $30 \mathrm{kGy}$.

the similar patterns (Fig. 4B). These results indicated that the degradation products of AMX, OFL, and CED possessed the similar chemical constitutions.

IC analysis. According to the previous studies, the organic pollutants could be mineralized into $\mathrm{CO}_{2}, \mathrm{H}_{2} \mathrm{O}$, and other inorganic substances by active radicals, and thus the concentrations of inorganic ions in degradation products were determined to evaluate the mineralization degrees of $\mathrm{ARs}^{19,21}$. As shown in Table 1, the concentrations of $\mathrm{NO}_{3}^{-}, \mathrm{SO}_{4}^{2-}$ and $\mathrm{F}^{-}$in the degradation products were determined, from which it could be calculated that the average mineralization degrees of AMX, OFL, and CED were $97.02 \%, 97.61 \%$ and $96.87 \%$, respectively. This result demonstrated that the ARs were degraded into inorganic ions including $\mathrm{NO}_{3}^{-}, \mathrm{SO}_{4}^{2-}$, and $\mathrm{F}^{-}$dominantly.

Mechanism study. HEEB irradiation of water (at $\mathrm{pH} 3.0-11.0$ ) saturated with $\mathrm{N}_{2}$ can generate various reactive species in the aqueous solution as shown in reaction $(1)^{22}$.

$$
\begin{aligned}
& \mathrm{H}_{2} \mathrm{O} \stackrel{\text { HEEB }}{\longrightarrow} \mathrm{OH} \cdot(0.27)+\mathrm{e}_{\mathrm{aq}}^{-}(0.27)+\mathrm{H} \cdot(0.06)+\mathrm{H}^{+}(0.27) \\
& \quad+\mathrm{H}_{2}(0.045)+\mathrm{H}_{2} \mathrm{O}_{2}(0.07)
\end{aligned}
$$

The values in parentheses represent the conversion efficiencies of generated particles during the HEEB irradiation. Among the chemical species formed during the radiolysis of water, $\mathrm{OH} \cdot \mathrm{e}_{\mathrm{aq}}^{-}$and $\mathrm{H} \cdot$ (reactions 1-3) probably displayed activities to different extents for the degradation of organic compounds ${ }^{20}$. In order to evaluate the contribution of each active particle to the degradation of ARs, several scavengers $\left(\mathrm{H}_{2} \mathrm{O}_{2}, \mathrm{i}-\mathrm{PrOH}\right.$, and t- $\left.\mathrm{BuOH}\right)$ were used to eliminate these active particles specifically (reactions 4-8): $\mathrm{H}_{2} \mathrm{O}_{2}$ for $\mathrm{e}_{\mathrm{aq}}^{-}$and $\mathrm{H}$, i- $\mathrm{PrOH}$ for $\mathrm{H}$. and $\mathrm{OH} \cdot \mathrm{t}-\mathrm{BuOH}$ for $\mathrm{OH}^{15,19-23}$. According to previous studies, the contribution of $\mathrm{OH} \cdot$ could be easily assessed in aerated antibiotic solutions, because $\mathrm{e}_{\mathrm{aq}}^{-}$and $\mathrm{H}$ - were easily scavenged by oxygen and rapidly converted into $\mathrm{HO}_{2}$. (equations 2 and 3) ${ }^{15,19-21}$. As shown in reactions (4) and (5), $\mathrm{e}_{\mathrm{aq}}^{-}$and $\mathrm{H}$. could be oxidized into $\mathrm{OH} \cdot$ by $\mathrm{H}_{2} \mathrm{O}_{2}{ }^{23,24}$.

$$
\begin{aligned}
& \mathrm{e}_{\mathrm{aq}}^{-}+\mathrm{O}_{2} \rightarrow \mathrm{O}_{2} \cdot^{-} \\
& \mathrm{H} \cdot+\mathrm{O}_{2} \rightarrow \mathrm{HO}_{2} .
\end{aligned}
$$




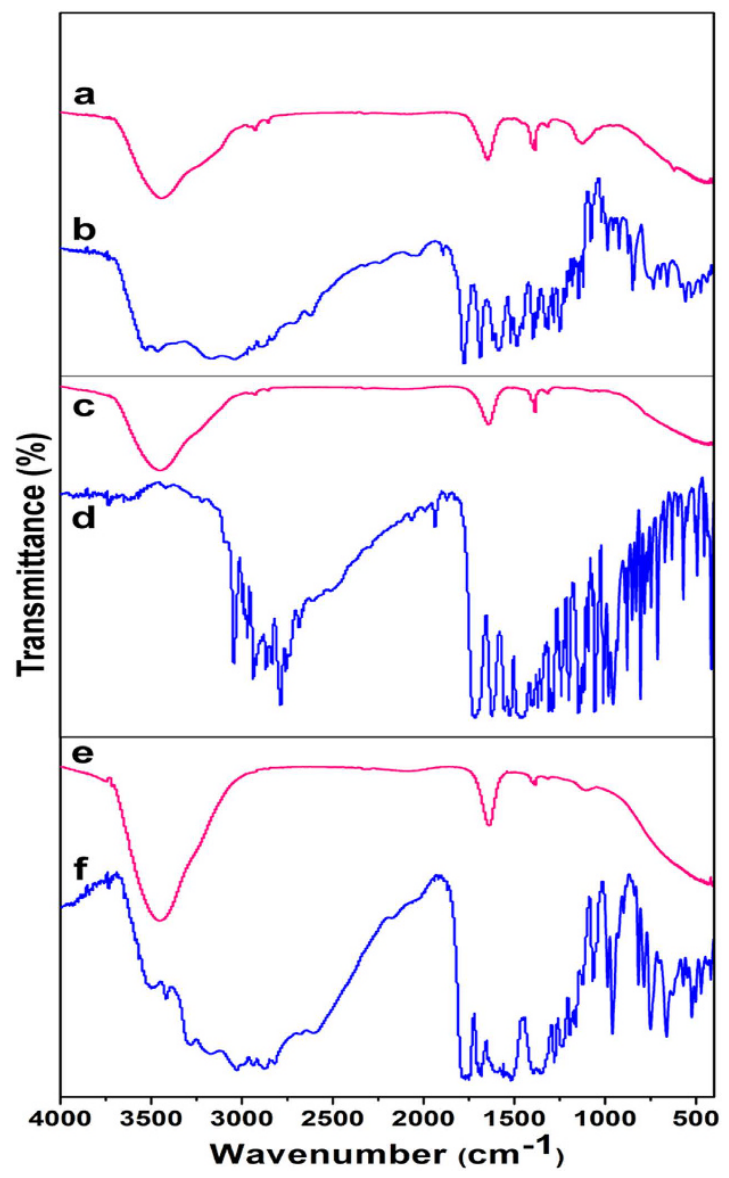

Figure 3. FTIR spectra of samples: (a) AMX $\left(50 \mathrm{mg} \mathrm{L}^{-1}\right)$ after degradation at dose of $30 \mathrm{kGy}$ with $\mathrm{pH}$ of 9.0, (b) AMX, (c) OFL after degradation at dose of $30 \mathrm{kGy}$ with $\mathrm{pH}$ of 9.0, (d) OFL $\left(50 \mathrm{mg} \mathrm{L}^{-1}\right)$, (e) CED after degradation at dose of $300 \mathrm{kGy}$ with $\mathrm{pH}$ of 9.0 , (d) CED $\left(50 \mathrm{mg} \mathrm{L}^{-1}\right)$.

$$
\begin{gathered}
\mathrm{H}_{2} \mathrm{O}_{2}+\mathrm{e}_{\mathrm{aq}}^{-} \rightarrow \mathrm{OH} \cdot+\mathrm{OH}^{-} \\
\mathrm{H}_{2} \mathrm{O}_{2}+\mathrm{H} \cdot \rightarrow \mathrm{OH} \cdot+\mathrm{H}_{2} \mathrm{O} \\
\mathrm{H} \cdot+\mathrm{i}-\mathrm{PrOH} \rightarrow\left(\mathrm{CH}_{3}\right)_{2} \cdot \mathrm{COH}+\mathrm{H}_{2} \\
\mathrm{OH} \cdot+\mathrm{i}-\mathrm{PrOH} \rightarrow\left(\mathrm{CH}_{3}\right)_{2} \cdot \mathrm{COH}+\mathrm{H}_{2} \mathrm{O} \\
\mathrm{OH} \cdot+\mathrm{t}-\mathrm{BuOH} \rightarrow \mathrm{HOC}\left(\mathrm{CH}_{3}\right)_{2} \mathrm{CH}_{2} \cdot+\mathrm{H}_{2} \mathrm{O}
\end{gathered}
$$

As shown in Fig. 5, after HEEB irradiation (30 kGy), the DEs of all the ARs with different scavengers (air, $\mathrm{H}_{2} \mathrm{O}_{2}$, i- $\mathrm{PrOH}$, and $\left.\mathrm{t}-\mathrm{BuOH}\right)$ displayed the same order $\left(\mathrm{H}_{2} \mathrm{O}_{2}>\right.$ air $\left.>t-\mathrm{BuOH}>\mathrm{i}-\mathrm{PrOH}\right)$, which indicated that $\mathrm{OH}$. was probably the dominant active particle for the degradation of ARs, and other active particles such as $\mathrm{H}$. and $\mathrm{e}_{\mathrm{aq}}^{-}$were also responsible for the degradation of ARs in some degree.

Effect of coexisting substances on the degradation of ARs. The influences of a series of substances such as nitrite $\left(\mathrm{NO}_{2}^{-}\right)$, nitrate $\left(\mathrm{NO}_{3}^{-}\right)$, carbonate $\left(\mathrm{CO}_{3}^{2-}\right)$, bicarbonate $\left(\mathrm{HCO}_{3}^{-}\right)$, ferric $\left(\mathrm{Fe}^{3+}\right)$, and humic acid (HA) on the degradation of ARs were investigated respectively. These substances except $\mathrm{HA}$ tended to react with $\mathrm{OH}$, $\mathrm{H} \cdot$, and $\mathrm{e}_{\mathrm{aq}}^{-}$ (reactions 9-15) and thus scavenged these radicals to a great extent, while HA could only react with and scavenge $\mathrm{OH}$ - according to previous study ${ }^{20}$. It was clearly shown in Table 2 that the DEs of AMX, OFL, and CED with these substances were all lower compared with the corresponding antibiotic alone, suggesting the significant competing effects with antibiotic molecules on $\mathrm{OH}^{\cdot 19-23}$. This result could also prove the key role of $\mathrm{OH}$ - in the degradation process of antibiotics.

$$
\mathrm{e}_{\mathrm{aq}}^{-}+\mathrm{NO}_{3}^{-} \rightarrow \mathrm{NO}_{3}^{2-}
$$



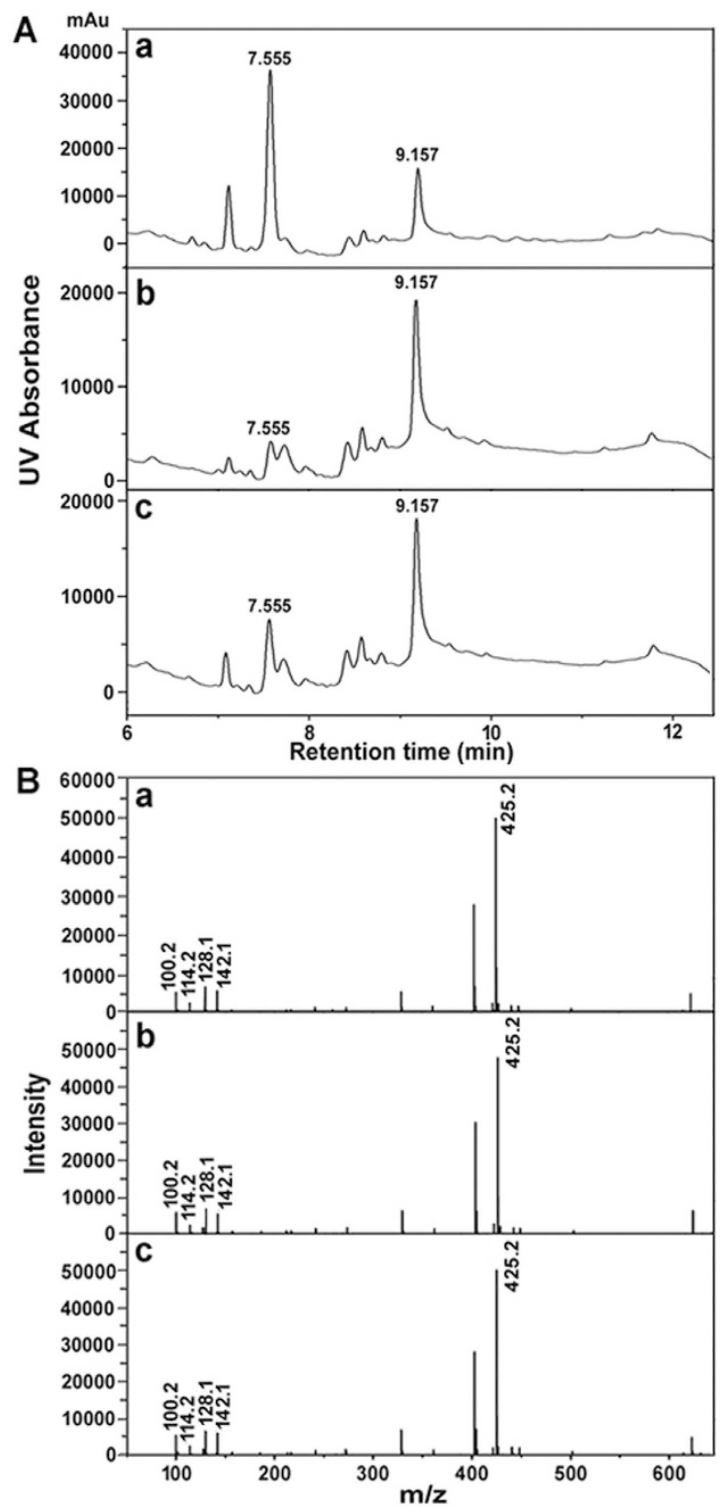

Figure 4. (A) HPLC chromatograms of degradation products of AMX (a), OFL (b), and CED (c), (B) MS spectra of degradation products of AMX (a), OFL (b), and CED (c) collected at retention time of $9.157 \mathrm{~min}$ after HPLC treatment.

\begin{tabular}{|c|c|c|c|c|c|c|c|c|c|}
\hline \multirow[b]{2}{*}{ Sample } & \multirow[b]{2}{*}{$\operatorname{MIC}\left(\mathbf{m g ~ L ^ { - 1 }}\right)$} & \multicolumn{3}{|c|}{ AMX } & \multicolumn{3}{|c|}{ OFL } & \multicolumn{2}{|c|}{ CED } \\
\hline & & TIC $\left(\mathrm{mg} \mathrm{L}^{-1}\right)$ & MD (\%) & $\operatorname{MIC}\left(\mathrm{mg} \mathrm{L}^{-1}\right)$ & TIC $\left(\mathrm{mg} \mathrm{L}^{-1}\right)$ & MD (\%) & MIC $\left(\mathrm{mg} \mathrm{L}^{-1}\right)$ & $\operatorname{TIC}\left(\mathrm{mgL}^{-1}\right)$ & MD (\%) \\
\hline $\mathrm{F}^{-}$ & 1 & 1 & & 2.57 & 2.63 & 97.71 & 1 & 1 & \\
\hline $\mathrm{NO}_{3}^{-}$ & 24.69 & 25.45 & 97.01 & 25.12 & 25.76 & 97.51 & 25.79 & 26.62 & 96.88 \\
\hline $\mathrm{SO}_{4}^{2-}$ & 12.75 & 13.14 & 97.03 & 1 & 1 & & 13.31 & 13.74 & 96.87 \\
\hline
\end{tabular}

Table 1. Measured ion concentration (MIC), theoretical ion concentration (TIC), and mineralization degree (MD) of degradation products.

$$
\begin{gathered}
\mathrm{H} \cdot+\mathrm{NO}_{3}^{-} \rightarrow \mathrm{HNO}_{3}^{-} \\
\mathrm{OH} \cdot+\mathrm{NO}_{2}^{-} \rightarrow \mathrm{NO}_{2} \cdot+\mathrm{OH}^{-} \\
\mathrm{e}_{\mathrm{aq}}^{-}+\mathrm{Fe}^{3+} \rightarrow \mathrm{Fe}^{2+}
\end{gathered}
$$




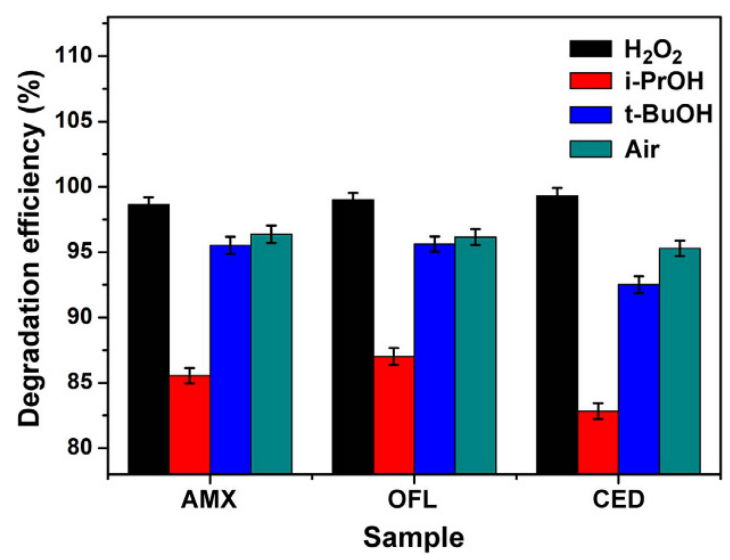

Figure 5. DEs of ARs ( $\left.50 \mathrm{mg} \mathrm{L}^{-1}\right)$ after irradiation ( $\left.30 \mathrm{kGy}\right)$ under the conditions of air alone, $\mathrm{H}_{2} \mathrm{O}_{2}(0.01 \mathrm{M})$, i-PrOH $(0.01 \mathrm{M})$, and $\mathrm{t}-\mathrm{BuOH}(0.01 \mathrm{M})$, respectively.

\begin{tabular}{|l|c|c|c|c|c|c|c|}
\hline Sample & Aerated only & $\mathrm{NO}_{2}^{-}$ & $\mathbf{N O}_{3}^{-}$ & $\mathbf{H C O}_{3}^{-}$ & $\mathbf{C O}_{3}^{2-}$ & $\mathbf{F e}^{3+}$ & $\mathbf{H A}$ \\
\hline AMX & $97.52 \%$ & $80.38 \%$ & $90.50 \%$ & $54.92 \%$ & $80.25 \%$ & $92.67 \%$ & $81.96 \%$ \\
\hline OFL & $98.91 \%$ & $77.86 \%$ & $91.61 \%$ & $60.14 \%$ & $76.76 \%$ & $95.38 \%$ & $85.72 \%$ \\
\hline CED & $98.10 \%$ & $81.75 \%$ & $90.76 \%$ & $61.06 \%$ & $88.64 \%$ & $96.29 \%$ & $83.30 \%$ \\
\hline
\end{tabular}

Table 2. DEs of ARs in the presence of substances $\left(\mathrm{NO}_{2}^{-}, \mathrm{NO}_{3}^{-}, \mathrm{CO}_{3}^{2-}, \mathrm{HCO}_{3}^{-}, \mathrm{Fe}^{3+}\right.$, and $\left.\mathrm{HA}\right)$. Experimental conditions: HEEB irradiation dose of $30 \mathrm{kGy}, \mathrm{pH}=9.0,[\mathrm{AR}]=50 \mathrm{mg} \mathrm{L}^{-1}$, [inorganic ions] $=1 \mathrm{M}$, and $[\mathrm{HA}]=35 \mathrm{mg} \mathrm{L}^{-1}$.

$$
\begin{gathered}
\mathrm{OH} \cdot+\mathrm{CO}_{3}^{2-} \rightarrow \mathrm{CO}_{3} \cdot-\mathrm{OH}^{-} \\
\mathrm{e}_{\mathrm{aq}}^{-}+\mathrm{HCO}_{3}^{-} \rightarrow \text { Product } \\
\mathrm{OH} \cdot+\mathrm{HCO}_{3}^{-} \rightarrow \mathrm{CO}_{3} \cdot-+\mathrm{H}_{2} \mathrm{O}
\end{gathered}
$$

\section{Conclusions}

In summary, three common ARs (AMX, OFL, and CED) in MIIBs were successfully degraded by HEEB irradiation, which could generate plenty of active particles and then effectively degrade ARs in situ. It was found that the maximum degradation efficiency was achieved at an initial AR concentration of $50 \mathrm{mg} \mathrm{L}^{-1}$ with an irradiation dose of $30 \mathrm{kGy}$ at $\mathrm{pH}$ 9.0. FTIR and HPLC-MS analyses illustrated that the degradation products of antibiotics mainly consisted of inorganic ions and alkane. Mechanism analysis indicated that the degradation of ARs was mainly induced by $\mathrm{OH}$. generated during the irradiation process. Additionally, a series of substances coexisting in ARs could affect the degradation performance via reacting with $\mathrm{OH}$. In a word, this work provided a promising and in situ degradation method for ARs.

\section{Methods}

Materials. $\quad \operatorname{AMX}(\geq 99 \%)$, OFL ( $\geq 99 \%), \mathrm{CED}(\geq 99 \%)$, and terephthalic acid (TA, 98\%) were purchased from Aladdin Industrial Co., Ltd. (Shanghai, China). $\mathrm{H}_{2} \mathrm{O}_{2}$, i- $\mathrm{PrOH}, \mathrm{t}-\mathrm{BuOH}, \mathrm{HCl}$, and $\mathrm{NaOH}$ with analytical reagent grade were purchased from Sinopharm Chemical Reagent Co., Ltd. (Shanghai, China). Deionized water was used throughout this work. MIIBs (height of $11 \mathrm{~cm}$, bottom diameter of $5.3 \mathrm{~cm}$ and volume of $100 \mathrm{~mL}$ ) made up of propene polymer were obtained from Cancer Hospital, Hefei Institutes of Physical Science, Chinese Academy of Sciences.

Sample preparation. Antibiotic solutions $(50 \mathrm{~mL})$ with concentrations from 10 to $60 \mathrm{mg} \mathrm{L}^{-1}$ were prepared to simulate ARs by dissolving AMX, OFL or CED in MIIBs with deionized water. After that, the MIIBs were shaken $(100 \mathrm{rpm})$ for $5 \mathrm{~min}$ and then placed vertically for the treatment using HEEB accelerator ( $10 \mathrm{MeV}$ and $10 \mathrm{~kW}$ ) with irradiation doses of 10, 20,30, and $40 \mathrm{kGy}$, respectively. All experiments were performed at room temperature.

Degradation performance investigation. The degradation performances of AMX, OFL, and CED were investigated under different reaction conditions. After HEEB irradiation, the MIIBs were shaken (100 rpm) for $5 \mathrm{~min}$ and then the concentrations of ARs in MIIBs were determined. The degradation efficiency (DE) was calculated using the following equation: 


$$
D E=\left(\left(C_{0}-C_{t}\right) / C_{0}\right) \times 100 \%
$$

where $C_{0}$ and $C_{t}$ are the initial and residual concentrations of antibiotics, respectively $y^{9,15,18}$.

HPLC/MS analysis. The degradation product analysis was conducted on a mass spectrometer equipped with ESI sources connected to HPLC systems. Analyses were operated in negative ion mode with the mass scanning range of $50-1000 \mathrm{~m} / \mathrm{z}$. Isocratic chromatographic elution was performed on Eclipse XDB-C18 column $(250 \mathrm{~mm} \times 4.6 \mathrm{~mm}, 5 \mu \mathrm{m})$, using methanol-acetonitrile $(1: 1, \mathrm{v} / \mathrm{v})$ as a mobile phase. The mobile phase was pumped at a flow rate of $1 \mathrm{~mL} \mathrm{~min}^{-1}$ at room temperature. The injected sample volume was $10 \mu \mathrm{L}$. To elucidate the structures of degradation products, HPLC was coupled with a Q-TOF mass spectrometry.

Mechanism study on the degradation of antibiotics by HEEB irradiation. Before the HEEB irradiation, $\mathrm{H}_{2} \mathrm{O}_{2}(0.01 \mathrm{M})$, i- $\mathrm{PrOH}(0.01 \mathrm{M})$ or $\mathrm{t}-\mathrm{BuOH}(0.01 \mathrm{M})$ was added to the MIIBs containing antibiotic solutions, respectively, and then the solutions were saturated with $\mathrm{N}_{2}{ }^{24-26}$. The regular AMX, OFL, and CED solutions were prepared as controls. The resulting MIIBs were shaken $(100 \mathrm{rpm})$ for $5 \mathrm{~min}$ and then irradiated by the HEEB accelerator $(10 \mathrm{MeV}$ and $10 \mathrm{~kW})$ with dose of $30 \mathrm{kGy}$ at room temperature. Finally, the antibiotic solutions in MIIBs were analyzed to investigate the degradation mechanism.

Characterizations. The concentrations of antibiotics were determined using a UV-vis spectrophotometer (UV 2550, Shimadzu Co., Japan) at $228.3 \mathrm{~nm}$ (AMX), $293 \mathrm{~nm}$ (OFL), and $264 \mathrm{~nm}$ (CED). The degradation products were analyzed by a Fourier transform infrared (FTIR) spectrometer (Bruker Co., Germany) and a mass spectrometer (MS) equipped with ESI sources (Agilent 6120, USA) connected to high performance liquid chromatography (HPLC) systems (Agilent 1200 infinity, USA). The anions contents in degradation products were analyzed by ion chromatography (IC) (ICS-3000, Dionex Co., USA).

\section{References}

1. Li, R. Z. et al. Photoelectrocatalytic degradation of ofloxacin using highly ordered $\mathrm{TiO} 2$ nanotube arrays. Electrocatalysis 5, 379-386 (2014).

2. Klauson, D. et al. Aqueous photocatalytic oxidation of amoxicillin. Catal. Today 151, 39-45 (2010).

3. Tahira, Q. et al. LC/UV determination of cefradine, cefuroxime, and cefotaxime in dairy milk, human serum and wastewater samples. Springer Plus 2, 575 (2013).

4. Junejo, Y., Güner, A. \& Baykal, A. Synthesis and characterization of amoxicillin derived silver nanoparticles: Its catalytic effect on degradation of some pharmaceutical antibiotics. Appl. Surf. Sci. 317, 914-922 (2014).

5. Qi, F. F., Huang, M. H., Zheng, Y. \& Xu, Q. Optimization of an $\mathrm{A}^{2} / \mathrm{O}$ process for tetracycline removal via response surface methodology coupled with a Box-Behnken design. J. Environ. Sci. Health Part A 50, 735-743 (2015).

6. Zha, S. X. et al. Nanoscale zero-valent iron as a catalyst for heterogeneous Fenton oxidation of amoxicillin. Chem. Eng. J. 255, 141-148 (2014)

7. Marco, P. et al. Complete mineralization of the antibiotic amoxicillin by electro-Fenton with a BDD anode. J. Appl. Electrochem. 44, 1327-1335 (2014).

8. Meritxell, G. et al. Biodegradation of the X-ray contrast agent iopromide and the fluoroquinolone antibiotic ofloxacin by the white rot fungus Trametes versicolor in hospital wastewaters and identification of degradation products. Water Res. 60, 228-241 (2014).

9. Urszula, H. et al. Separation and characterization of ciprofloxacin, difloxacin, lomefloxacin, norfloxacin, and ofloxacin oxidation products under potassium permanganate treatment in acidic medium by UPLC-MS/MS. Talanta 109, 91-100 (2013).

10. Jiang, M. X., Wang, L. H. \& Ji, R. Biotic and abiotic degradation of four cephalosporin antibiotics in a lake surface water and sediment. Chemosphere 80, 1399-1405 (2010).

11. Li, K. et al. Concentration-dependent photodegradation kinetics and hydroxyl-radical oxidation of phenicol antibiotics. Chemosphere 111, 278-282 (2014).

12. Andreozzi, R., Canterino, M., Marotta, R. \& Paxeus, N. Antibiotic removal from wastewaters: The ozonation of amoxicillin. J. Hazard. Mater. 122, 243-250 (2005).

13. Guo, R. X., Wang, Z. L., Li, G. P. \& Chen, J. Q. Adsorption of cefradine onto powder and activated carbon prepared from orange peel. Applied Mechanics and Materials 470, 11-14 (2014).

14. Dimitrakopoulou, D. et al. Degradation, mineralization and antibiotic inactivation of amoxicillin by $\mathrm{UV}-\mathrm{A} / \mathrm{TiO} \mathrm{P}_{2} \mathrm{photocatalysis}$. J. Environ. Manage. 98, 168-174 (2012).

15. Zhou, J. X. et al. E-beam degradation of thiamphenieol and florfenieol. Nucl. Sci. Tech. 21, 334-338 (2010).

16. Chung, B. Y. et al. Degradation of ampicillin in pig manure slurry and an aqueous ampicillin solution using electron beam irradiation. Radiat. Phys. Chem. 78, 711-713 (2009).

17. Kim, H. Y. et al. Radiolysis of selected antibiotics and their toxic effects on various aquatic organisms. Radiat. Phys. Chem. 78, 267-272 (2009).

18. Weng, X. L. et al. Enhancement of catalytic degradation of amoxicillin in aqueous solution using clay supported bimetallic Fe/Ni nanoparticles. Chemosphere 103, 80-85 (2014).

19. $\mathrm{Li}, \mathrm{Y}$. Q. et al. In situ fabrication of $\mathrm{Mn}_{3} \mathrm{O}_{4}$ decorated graphene oxide as a synergistic catalyst for degradation of methylene blue. Appl. Catal. B Environ. 162, 268-274 (2015).

20. Sheydaei, M., Aber, S. \& Khataee, A. Degradation of amoxicillin in aqueous solution using nanolepidocrocite chips/ $\mathrm{H}_{2} \mathrm{O}_{2} / \mathrm{UV}$ Optimization and kinetics studies. J. Ind. Eng. Chem. 20, 1772-1778 (2014).

21. Wang, Q., Zhang, J. P., Zheng, Y. \& Wang, A. Q. Adsorption and release of ofloxacin from acid- and heat-treated halloysite. Colloid Surf. B-Biointerfaces 113, 51-58 (2014).

22. Shah, N. S., Khan, J. A., Nawaz, S. \& Khan, H. M. Role of aqueous electron and hydroxyl radical in the removal of endosulfan from aqueous solution using gamma irradiation. J. Hazard. Mater. 278, 40-48 (2014).

23. Zhang, S. J., Yu, H. Q. \& Zhao, Y. Kinetic modeling of the radiolytic degradationof Acid Orange 7 in aqueous solutions. Water Res. 39, 839-846 (2005).

24. Zaki, A. A. \& Elgendy, N. A. Removal of metal ions from wastewater using $\mathrm{EB}$ irradiation in combination with $\mathrm{HA} / \mathrm{TiO} \mathrm{O}_{2} / \mathrm{UV}$ treatment. J. Hazard. Mater. 271, 275-282 (2014).

25. Zhang, S. J. et al. Kinetics and mechanisms of radiolytic degradation of nitrobenzene in aqueous solutions. Environ. Sci. Technol. 41, 1977-1982 (2007).

26. Elmolla, E. S. \& Chaudhuri, M. Degradation of amoxicillin, ampicillin and cloxacillin antibiotics in aqueous solution by the UV/ $\mathrm{ZnO}$ photocatalytic process. J. Hazard. Mater. 173, 445-449 (2010). 


\section{Acknowledgements}

The authors acknowledge financial support from the National Natural Science Foundation of China (No. 21407151), the Key Program of Chinese Academy of Sciences (No. KSZD-EW-Z-022-05), the Science and Technology Service Programs of Chinese Academy of Sciences (Nos. KFJ-EW-STS-083, KFJ-EW-STS-067, and KFJ-SW-STS-143-4), and the Grant of the President Foundation of Hefei Institutes of Physical Science of Chinese Academy of Sciences (No. YZJJ201502).

\section{Author Contributions}

X.Z., D.C. and Z.W. conceived the research. M.W. performed the experiments. M.W. and L.Z. performed the characterization. M.W., G.Z. and T.P. analyzed the data. D.C. gave constructive comments on the results. M.W. wrote the manuscript. X.Z., D.C. and Z.W. provided the research fundings.

\section{Additional Information}

Competing financial interests: The authors declare no competing financial interests.

How to cite this article: Wang, M. et al. In situ degradation of antibiotic residues in medical intravenous infusion bottles using high energy electron beam irradiation. Sci. Rep. 7, 39928; doi: 10.1038/srep39928 (2017).

Publisher's note: Springer Nature remains neutral with regard to jurisdictional claims in published maps and institutional affiliations.

(c) (i) This work is licensed under a Creative Commons Attribution 4.0 International License. The images or other third party material in this article are included in the article's Creative Commons license, unless indicated otherwise in the credit line; if the material is not included under the Creative Commons license, users will need to obtain permission from the license holder to reproduce the material. To view a copy of this license, visit http://creativecommons.org/licenses/by/4.0/

(C) The Author(s) 2017 